\title{
A Panoramic Evaluation of Literary Texts in Preparatory Students’ English Text Books
}

\author{
Gedefaw Abie Kebede \\ English Language and Literature Department, Debre Markos University, Ethiopia \\ Yihenew Melese Milkitie \\ English Language and Literature Department, Debre Markos University, Ethiopia
}

\begin{abstract}
Learning language through literature has got a great emphasis in foreign language class room since the use of literary text as a resource for teaching macro and micro skills is very popular within the field of language learning. Literary texts increase the learners' proficiency of integrated language learning as they enable the learners to apply all macro and micro skills. Of the issues to be considered, the contents, their levels of difficulty, their diversity and the appropriateness of the tasks designed based on the contents. This study evaluated the literary texts in preparatory students English text books. Based on the objectives of the study, both qualitative and quantitative research method was employed. The result of the study indicated that the most of the literary texts are above the language competence of the students and the teachers. Teachers strongly affirmed that they have faced to understand the literary texts' language. The literary texts are not considering the students' cultural background since almost all of the texts are written by foreign in a foreign context. Moreover, the majority of the literary texts are not related with the unit topic of the book. Using the literary materials in language class, therefore, should take into account the students' need, motivation, interests, cultural background and language competence.
\end{abstract}

Index Terms - panoramic, evaluation, literary text, text book

\section{INTRODUCTION}

\section{A. Background}

English, being an international language, has a pivotal significance in disseminating knowledge skills and attitudes to both teachers and students at all levels. In Ethiopia, on top of being taught as a subject in its own right at all grade levels, English has been used as medium of instruction in secondary schools and higher education institutions. This makes English Language learning and teaching in the country needs a serious attention due to such reasons.

Of the inputs needed to teach and learn languages, including English, literature is one. Literature is a primary material of teaching a target language, providing authentic and real contexts of communicative situations. It also provides the pleasure of learning a new language with and through interesting stories. Students can extend their knowledge and experience of the world by interacting through literature. A language teacher could encourage students to make discourses in literature to extract their own meanings, bringing their experiences into play. Instead of being forced to perceive a text only the teacher's way, students will explore it in light of their experiences .Literature also shows students new ways to view the world around them by constructing meaning from the text (Mohammad, Amir \$ Rahimi, 2012).

Learning and teaching language through literature is, therefore, worth pondering over for both language teachers and language teaching material developers (Sage 1987). Incorporating literary text in language class room has got attention due its richness, variety and stimulating power for language learners. This would mean that a literary text stimulates imagination of the learners, offers specimens of authentic use of language and provides ample opportunities for discussions of the issues which are conveyed in the given texts. It increases students' personal involvement in the learning process and bridges the gaps between the cultures and makes them familiar with the norms and behaviors of the people of the target language. Thus, the use of literary text in language class can act as a means of cultural enrichment. It helps the learners get familiar with the socio-political backgrounds of a target language; it makes them understand how communication works in a particular community. This broadens their horizon of understanding the common human nature (Nellufar, Abul, Kalam, \$ Jannatul, 2011).

Since literature and language are closely related, the use of literary text as a resource for macro and micro skills (is very popular within the field of language learning and teaching. In line with this, McKay (1982) argues that, in literary works, the rich context helps increase the awareness of the students about language use. Literary texts increase the learners' proficiency of integrated language learning because they give opportunities for the learner to utilize all macro and micro skills together.

Similarly, Kramsch (1993) argued that reading could be perceived as the interaction between readers and the text; the reader should be willing and motivated to read. Creative literature, therefore, can be considered as a tool for motivating 
the learners of language. The improvement of reading proficiency leads to achievement in academic and occupational goals. As the same time, it develops tolerance for cultural differences and promotion of creativity in the students. As result of reading literary texts, the students can access information about historical and cultural values of the world.

In recent years, the role of literature is taken as a basic component and source of a language curriculum. This is one of the reasons that many teachers consider the use of literature in language teaching as an interesting and worthy concern (Sage 1987). Collie and Slater (1990) suggested four main reasons which attracts language teacher to use literature in the classroom. Frist reason is that literature is authentic material. Another reason is that literary material can be a source of language teaching due its cultural enrichment and language enrichment. Moreover, it increases the personal involvement of the learners. In addition to these, universality, non-triviality, personal relevance, variety, interest, economy and suggestive power and ambiguity are some other factors which make literature a powerful resource in a language classroom context.

As mentioned above, many scholars suggested that literary text give ample of benefits for students. The texts help the students to identify the syntactic structure between written and spoken discourses. Besides, it enables the students to increase their word power of the target language. Based on its abundance benefits of the learner, incorporating literary text in language teaching is a worthy criterion.

The previous Ethiopian curricula of all grade levels were much blamed for being teacher-centered. The Ethiopian new education system claims to have made a shift to a learner centre approach. The main task of modern educationists and educational institutions, including those working on language, should accordingly be shattering the traditional notion in which students view teachers as the sole keepers and deliverers of knowledge; it shall not only brainwash the students but also train them on how to learn more by themselves.

The new preparatory English text books contain different genres of literary text in contrast to the previous rule- based (grammar-focused) texts. These literary texts, if wisely selected and exploited, could both shape students thinking and develop their language competence. They should thus be assessed depending on certain established criteria of language material evaluation.

\section{B. Statement of the Problem}

Though literary texts are very essential for language teaching, it is very important to consider the types of text in term of content, culture and language difficulty. When we select literary texts to be used in language classes, we should take into account students' motivation towards the selected text, cultural background and language competence. Moreover, a prominent factor to take into account is that the selected text should stimulate the learners' interest since learners invest their time on reading literary texts; thus the texts are more likely to have a long-term and valuable effect upon the learners' linguistic and extralinguistic knowledge when it is wisely and meaningfully constructed. Language difficulty has to be considered as well in selecting the texts if the language of the literary work is simple, it may facilitate the comprehensibility of the literary text by the learners; however, this is not the most crucial criterion. In addition, material developers consider as a prominent criteria are interest, appeal, and relevance of the texts. If the material is enjoyable enough, it offers a fresh insight into issues felt to be related to the learners' concerns and other relevant issues need to be assessed to judge if a literary material is proper for any grade level under consideration (Collie and Slater 1990).

In Ethiopia, students' text books are prepared by the Federal Minster of Education and teachers teach using these prescribed materials. This is the case with preparatory students' English texts as well. It is simply a matter of chance for the text books to be palatable and constructive to the teacher and the students or not. It is therefore important to scrutinize the text books in general and the literary materials in particular in line with acceptable frames of evaluation. Of the issues to be considered are the contents, their levels of difficulty, their diversity and the appropriacy of the tasks designed based on the contents. Literary texts in current preparatory school English text books yield themselves for a panoramic study based on such criteria. The following research questions are sorted out to assess the literary materials in the books:

- are the language levels challenging only sufficiently?

-are the literary materials culturally appropriate to the learner?

-are the materials exploited?

\section{Objectives}

As a general objective, the study aims to make a panoramic Evaluation of Literary Texts in Preparatory English Text Books.

The specific objectives of the study are the following:

- To assess literary text's language level

- To evaluate the cultural appropriacy of the literary materials

- To assess the relevance of the text with unit topic

\section{Significance}

The researchers believe that the study has different importance. Primarily, the findings of the study will be used for policy makers. Policy makers will use the result to take reforms on English text books. Text book designers will use the 
finding as an input. Furthermore, English teachers will be benefited from the finding of the study. Besides, the study will serve as a stepping stone for those who have an interest to conduct further study in this area.

\section{E. Scope}

This study focused on literary texts in preparatory English text books for grade 11 and 12. The study was made only at Debre Markos preparatory school. Constraints of time and resource have forced the researchers to limit their scope to two grade levels and see the issue in focus just at one school.

\section{LITERATURE REVIEW}

\section{Why Use Literary Materials in Language Teaching?}

The uses of literary texts in the language classroom and in second language education are numerous .Literature and language teaching have not separable because directly or indirectly the language teacher utilizes literature in language classroom due to its resourcefulness and suggestiveness. Many scholars are advocating that using literature in language class is a best way of teaching the target language.

Literature, therefore, is unquestionably useful in the development of the four language skills. Afolayan (1972) argues that it is "unthinkable that a second language should be taught alone in the pure state as it were without literature. Language is a scheme, a mould whose substance is either Literature or Civilization, (p.27)". This argument depicts the strong integration of teaching language and literature as it is a means to manipulate the target language in the actual classroom. Similarly, Palmer (1968), in line with the methodological aspect, states that literature is the application of linguistic science and not the science of language itself.

In broad sense, of the demand of teaching language in the class along with linguistic benefits, exposure to literature stimulates learners to reflect their feelings, assumptions and believes regarding to the concepts which are stated in the materials. Provided that, learners able to recognize real life problems, explore causes and solutions, and compare their values and life styles with other cultures (Aly, 2012). Furthermore (Sii, Mee, \$ Chen Siew,2016) in the curriculum, in which the aim of English as a subject in school is not only used for academic purpose but also it enables to understand the social environment and the cultural aspects in which they are living through From the above express, we can understand that literature has a remarkable significance for the students in language class as it is inclusively used to learn the target language and t life experience from the world environment. The status and benefit of literature in language class is discussed by many scholars. Among these, (Lazar, 1993; McKay, 1982; Widdowson, 1984) put their arguments on essentiality of literature in language class as it is the way to facilitate the development of language proficiency as well as cultural awareness of the learners.

McKay (1982) claims that one of the most important contributions of using literature for language teaching purposes is that "literature presents language in discourse" (p.530), which will exemplify why a specific language form should be used in the actual practice. This may contribute to the development of students' language awareness. Likewise, (Roe and Ross, 2015) point out that literary texts provide language models such as sentence structure, standard story structure, and new vocabulary to students; it also literary texts can help students to activate imagination and develop their emotion. They believed that literary texts foster students' reading proficiency, promoting tolerance for cultural differences, and leading the students to be more creative. The literary texts help the students to develop basic English skills, for example, if the student gets the opportunity of listening the literary materials when read aloud by the teacher or students, he/she will be motivated to discuss on literary texts. The student speaks when he acts in the plays in actual practice, read poems and messages and when he is encouraged to participate actively in literary discussions if the literary texts are impressive.

In addition to the above benefits, literary texts enable the students to gain new perceptions of other cultures and societies through literary texts (Babaee and Yahya, 2014). Lastly, literary texts can be taught to promote students' critical reading and thinking skills in the EFL classroom (Kohzadi, Azizmohammadi \& Sanadi, 2014). In this context, if the students have exposure to fine literary texts, they can develop a long-lasting appetite of reading that is used as an input to learn other language skills.

Considering its importance, selecting literary text demands critical attention. Selection of reading materials is very important for teaching the skills of critical reading in an EFL classroom (Mokhtari, 2014). Teachers should carefully select reading materials which can benefit EFL students in enhancing their critical reading skills.

\section{Methodology}

\section{A. Study Design}

This research was both qualitative and quantitative.

\section{B. Study Population}

English teachers who were working in the study area, teaching the specified grades and subject, along with their students were taken as a source population for this study.

\section{Sample Size Determination}


Due to the manageability of their number, all literary materials in preparatory English text books and all preparatory school English language teachers were taken for the study. In addition, 385 samples were taken out of $\mathbf{1 7 7 0}$ students in both grade levels. To determine the sample, the researchers used single population proportion formula. Based on this method, the following assumptions were taken.

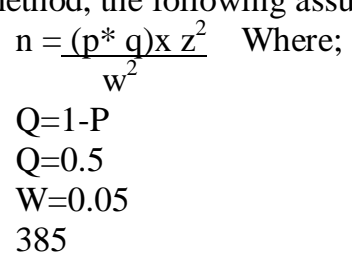

\section{Sampling}

The researchers used simple random sampling method to select sample students. As a sample frame, the students' attendance list was used. 385 samples were taken in proportion with the number of classes and students. This method was free from bias and it gave equal chance for each student to be selected.

\section{E. Data Collection Instruments}

The quantitative data was collected from the students through questionnaire. Besides, focus group discussion (FGD) was used to collect the qualitative data. The FGD is important to make genuine and face to face discussions with the subject teachers who are the primary implementers of the curriculum. The researchers developed a better rapport to make informative professional discussions on the pros and cons of the materials under study. The FGD were held two times. This was triangulated with the quantitative data which was collected through questionnaire. This may be minimizing the risks of shyness and secrecy that face to face methods may pose.

\section{F. Data Processing and Analysis}

The qualitative data was grouped in to several thematic areas which support the quantitative findings. In addition, the quantitative data was entered with EPI-data version3.1 software and it was analyzed by using SPSS version 20. Frequency, percentage, and tables were used to present quantitative data. The qualitative data were grouped and discussed in line with the quantitative data.

\section{DATA ANALYSIS AND DISCUSSION}

Literary texts are ample of benefits to the students. Among these, the respondents $153(45.9 \%)$ indicated that the literary texts used to increase word power. It means that the literary texts inserted in the text book enable the learners to develop their word power. The increment of the learners' word power has some sort of importance on the learners understanding skill of the text. Along this, the learners have exposure to new concepts and they can easily contextualize the new terms. They go beyond since they are familiar with the new words via the literary texts. Thus, they may not face word difficulty.

In addition, $90(27 \%)$ of the respondents confirmed that literary texts are used to develop reading skills. Since reading is the daily practice of the students, the literary texts become the habit of the learners. Reading and discussing literary texts are central to the teaching and learning practices of language because large proportion of class time is devoted to small group discussions or reading the literary texts incorporated in text. Therefore, it is very interesting to assess the literary texts in terms of manageable difficulty, interesting to the learners and relation to the unit. Accordingly, the texts are discussed below in different sub topics.

\section{A. Text Difficulty}

Text difficulty in this context refers to the relationship between the students language competence and the language level of the text. Literary texts utilized in accordance with the context in which they were written. But the difficult task is identifying their context.

Based on the linguistic and stylistic level of literary the texts 


\begin{tabular}{|c|c|c|c|c|c|c|c|c|c|c|c|}
\hline \multirow[t]{2}{*}{ No } & \multirow[t]{2}{*}{ Literary texts } & \multicolumn{2}{|c|}{ Strongly Agree } & \multicolumn{2}{|l|}{ Agree } & \multicolumn{2}{|l|}{ Neutral } & \multicolumn{2}{|l|}{ Disagree } & \multicolumn{2}{|c|}{ Strongly Disagree } \\
\hline & & $\begin{array}{l}\text { Frequenc } \\
\mathrm{y}\end{array}$ & Percent & $\begin{array}{l}\text { Freque } \\
\text { ncy }\end{array}$ & Percent & $\begin{array}{l}\text { frequenc } \\
\mathrm{y}\end{array}$ & $\begin{array}{l}\text { percen } \\
\mathrm{t}\end{array}$ & frequency & percent & Frequency & $\begin{array}{l}\text { Perc } \\
\text { ent }\end{array}$ \\
\hline 1 & The au anthem & 41 & 12.3 & 73 & 21.9 & 96 & 28.8 & 61 & 18.3 & 30 & 9 \\
\hline 2 & $\begin{array}{l}\text { Oweka learns a } \\
\text { lesson }\end{array}$ & 29 & 8.7 & 75 & 22.5 & 57 & 17.1 & 117 & 35.1 & 23.9 & 6.9 \\
\hline 3 & $\begin{array}{l}\text { Night of a } \\
\text { scorpion }\end{array}$ & 40 & 12 & 77 & 23.1 & 54 & 16.2 & 83 & 24.9 & 47 & 14.1 \\
\hline 4 & Operation rhino & 52 & 15.6 & 58 & 17.4 & 52 & 15.6 & 97 & 29.1 & 42 & 12.6 \\
\hline 5 & mingual street & 35 & 10.5 & 73 & 21.9 & 58 & 17.4 & 87 & 26.1 & 48 & 14.4 \\
\hline 6 & -Tale of a tap & 20 & 6 & 89 & 26.7 & 64 & 19.2 & 81 & 24.3 & 47 & 14.1 \\
\hline 7 & the African child & 4 & 1.2 & 54 & 16.2 & 57 & 17.1 & 73 & 21.9 & 22 & 6.6 \\
\hline 8 & $\begin{array}{l}\text { Why old woman } \\
\text { limps }\end{array}$ & 36 & 10.8 & 43 & 12.9 & 67 & 20.1 & 119 & 35.7 & 36 & 10.8 \\
\hline 9 & The narrow path & 31 & 9.3 & 58 & 17.4 & 76 & 22.8 & 77 & 23.1 & 59 & 17.7 \\
\hline 10 & $\begin{array}{l}\text { Building the } \\
\text { nation }\end{array}$ & 12 & 3.6 & 31 & 9.3 & 62 & 18.6 & 79 & 23.7 & 26 & 7.8 \\
\hline 11 & Vultures & 18 & 5.4 & 38 & 11.4 & 35 & 10.5 & 84 & 25.2 & 35 & 10.5 \\
\hline 12 & The money order & 4 & 1.2 & 57 & 17.1 & 39 & 11.7 & 82 & 24.6 & 28 & 8.4 \\
\hline 13 & Total & & 30.5 & & & & & & 69.5 & & \\
\hline
\end{tabular}

The above literary texts in the table are only found in grade $11^{\text {th }}$ students text books. These literary texts are found in different units of the texts. Accordingly, the texts are treated in terms of liker scale. Based on the students response on the manageability of the literary text, 'the AU Anthem', 96(28.8\%) of the respondents are neutral on the manageability of the students. On the other hand, $73(21.9 \%)$ of the respondents agreed on the manageability of the text; for them the text is manageable in terms difficulty with their educational level. The second text is 'Oweka learns a lesson'. The respondents $117(35.1 \%)$ stated that they are not agree with the manageable difficulty of text 'Oweka learns a lesson'. Since the majority of the respondents disagree with manageable difficulty of the text, it is beyond their capacity, or it is beyond their language competence level. Along this, 57(17.1\%) of the respondents are neutral with the question manageable difficulty of the text. But $29(8.7 \%)$ and $77(22.5 \%)$ of the respondents strongly agree and agree with manageable difficulty of the text respectively. The statistical proportion of the respondents indicated that majority of the respondents faced with difficulty of the text since it is not manageable for them. This might be due to unable to understand the text fully when the read it because of language and cultural barriers that existed between the student and the text. Since all most all of the texts are written in foreign language, they may not be related with the learners' culture along with language difficulty.

Similarly, grade $12^{\text {th }}$ students responded on the relationship between literary texts and the unit topics of the book are unrelated. Of which, $77(23.1 \%) 59(17.7 \%)$ of the respondents stated that they did not agree on the manageable difficulty of the text.

In line with this teachers strongly affirmed that the literary texts are not manageable to the learner even for them. Although, the degree of difficulty varies from text to text, they are so difficult to understand the language and the subject matter of the text.

Under the unit title 'Traditional and Modern Medicine' the literary text incorporated is 'Night of a scorpion'. As stated on the above table no.3, the text is not manageable for some of the respondents as $83(24.9 \%)$ and $47(14.1)$ of the respondents disagree and strongly disagree with text's manageable difficulty respectively.

On the other hand, $77(23.1 \%)$ and 40(12\%) of the respondents agreed and strongly agreed with manageable difficulty of the text respectively and $54(16.2 \%)$ of the respondents have neutral position with this text. For text 'Operation Rhino', 97(29.1\%)of the respondents disagreed on manageable difficulty of text. Besides, 42(12.6\%) of the respondents strongly disagreed with manageable of the text, Operation Rhino'; whereas, 58(17.4\%) and 52(15.6\%) of the respondents agreed and strongly agreed with manageability of the text respectively. Similarly, respondents $87(26.6)$ and 48(14.4\%) disagreed and strongly disagreed the manageable text,' -mingual street' respectively. Nevertheless, 73(21.9) and $35(10.5 \%)$ of the respondents agree and strongly agree with manageable difficulty of this text. As the data shows, most of the respondents confirmed that this text is challenging to them. The material may be difficult due to language, content and cultural barriers with the learners. The learners' language competence has its own impact on their understanding skills of the content of the text.

Based on the majority of the respondents' response, the language of the literary text is alien for the learners and they could not understand them. Accordingly, the language of a literary text helps students to integrate the language and make meaningful interpretations. In in contrast to this, the language of literary texts in preparatory English texts books are not suitable to the students. The texts are the more unfamiliar and advanced may decrease the students' engagement with designed tasks since they may rely too much on the teacher to paraphrase, clarify and explain the contents. Moreover, the teachers were asked to respond their view about the language level of the literary texts. Among them, one of the teacher said that "even myself as a teacher could not understand the language in which it is utilized in the texts". Besides, another teacher added that (however I believe that literary texts are one instrument of teaching language, I do not use them in the class since the language structure as well as the vocabulary are new to me; I simply skip them and I sometimes attempt to paraphrase those are written in the prose form. The students also become silent when I order them 
to read poetry and they are not eager to do tasks". Almost all of preparatory teachers suggested that the language difficulty is one of the challenges to interpret and explain the contents of the texts. The texts demand both the teachers and the students' literary background. As the participants stated, the students low language competence and the high level difficulty of the language prevents the students from being vocal to express their ideas and feelings.

In general, the teachers strongly affirmed that the literary texts are not manageable to the learner even for them. Although, the degree of difficulty varies from text to text, they are so difficult to understand the language and the subject matter of the text.

\section{B. Charming Levels of Texts}

Incorporating the literary texts in language class is to stimulate the students and increase their involvement in learning language because it provides meaningful and memorable context for processing and interpreting new language.

\begin{tabular}{|c|c|c|c|c|c|c|c|c|c|c|c|}
\hline \multirow[t]{2}{*}{ No } & \multirow{2}{*}{$\begin{array}{l}\text { Literary } \\
\text { texts }\end{array}$} & \multicolumn{2}{|c|}{ Strongly Agree } & \multicolumn{2}{|l|}{ Agree } & \multicolumn{2}{|l|}{ Neutral } & \multicolumn{2}{|l|}{ Disagree } & \multicolumn{2}{|c|}{ Strongly Disagree } \\
\hline & & Frequency & Percent & Frequency & Percent & Frequency & percent & frequency & percent & Frequency & percent \\
\hline 1 & $\begin{array}{l}\text { The au } \\
\text { anthem }\end{array}$ & 30 & 9 & 38 & 11.4 & 56 & 16.8 & 103 & 30.9 & 74 & 22 \\
\hline 2 & $\begin{array}{l}\text { Oweka } \\
\text { learns a } \\
\text { lesson }\end{array}$ & 31 & 9.3 & 58 & 17.4 & 76 & 22.8 & 77 & 23.1 & 59 & 17.7 \\
\hline 3 & $\begin{array}{l}\text { Night of } \\
\text { a } \\
\text { scorpion }\end{array}$ & 48 & 14.4 & 58 & 17.4 & 92 & 27.6 & 76 & 22.8 & 27 & 8.1 \\
\hline 4 & $\begin{array}{l}\text { Operation } \\
\text { rhino }\end{array}$ & 31 & 9.3 & 70 & 21 & 56 & 16.8 & 82 & 24.6 & 62 & 18.6 \\
\hline 5 & $\begin{array}{l}\text {-mingual } \\
\text { street }\end{array}$ & 20 & 6 & 36 & 10.8 & 105 & 31.5 & 93 & 27.9 & 47 & 14.1 \\
\hline 6 & $\begin{array}{l}\text {-Tale of a } \\
\text { tap }\end{array}$ & 48 & 14.4 & 58 & 17.4 & 92 & 27.6 & 76 & 22.8 & 27 & 8.1 \\
\hline 7 & $\begin{array}{l}\text {-the } \\
\text { African } \\
\text { child }\end{array}$ & 21 & 6.3 & 61 & 18.3 & 61 & 18.3 & 99 & 29.7 & 59 & 17.7 \\
\hline 8 & $\begin{array}{l}\text { Why old } \\
\text { woman } \\
\text { limps }\end{array}$ & 59 & 17.7 & 57 & 17.1 & 67 & 20.1 & 52 & 15.6 & 62 & 18.6 \\
\hline 9 & $\begin{array}{l}\text { The } \\
\text { narrow } \\
\text { path }\end{array}$ & 18 & 5.4 & 46 & 13.8 & 43 & 12.9 & 50 & 15 & 53 & 15.9 \\
\hline 10 & $\begin{array}{l}\text { building } \\
\text { the nation }\end{array}$ & 10 & 3 & 23 & 6.9 & 76 & 22.8 & 55 & 16.5 & 46 & 13.8 \\
\hline 11 & Vultures & 4 & 1.2 & 63 & 18.9 & 50 & 15 & 55 & 16.5 & 38 & 11.4 \\
\hline 12 & $\begin{array}{l}\text { The } \\
\text { money } \\
\text { order }\end{array}$ & 13 & 3.9 & 37 & 11.1 & 57 & 17.1 & 74 & 22.4 & 25 & 7.5 \\
\hline 13 & Total & 333 & 8.325 & 605 & 15.12 & 831 & 20.76 & 892 & 22.3 & 579 & 14.45 \\
\hline
\end{tabular}

A total of 103(30.9\%) respondents disagreed that on the text The AU Anthem's interesting to the learners. These respondents did not enjoy the text. Furthermore, 74(22\%) of the respondents out of 301 strongly disagree that literary texts which are inserted in preparatory English text books on the text's interesting to the learner, students. Thus, more than half of the respondents did not enjoy the literary text since it is not attractive to them. As literatures support that literary text which are used in language teaching should be interesting to the learners. Though the text should be means to motivate the learners, the text is not pleasing the respondents. One target of incorporating literary text is to increase social and personal involvement with enjoying the students even if the majority of the respondents could not find the text interestingly.

The result of the study was summarized into two groups based on texts' interestingness or not to the learners. The respondents' average response for each item indicates that most of the respondents don't agree on the texts' attractiveness to the learners since $57.56 \%$ of the respondents did not find the literary text pleasant or enjoyable to them. Only $23.44 \%$ of the respondents found the text interesting to them. As collie and Slater (1990) pointed out that text selection should be given careful attention. They suggested that the text selection must be depended on each particular group of students' motivation, cultural background and language proficiency. Based on the suggested criteria, texts in preparatory students' text books were prepared without considering the students' cultural background, academic level, language competence, experience of enjoying the text or literary background, the composition and suitability of the text. In contrast, the selected literary texts are alien and foreign the social and cultural background of the learners. The writers also those texts are foreign and they produced in the foreign context. This means that the texts are not localized in Ethiopian context. These will bring a great failure to teach the target language integratively through literary texts.

Accordingly, the cumulative statistics shows that literary texts which inserted in the preparatory literary texts are not interesting to the majority of the respondents. One of the qualities of literary text is enjoyable and simulative to the learner, but most of the respondents could not find this quality from the text books. 


\section{Relation to the Unit}

Selecting text in language classroom needs a serious attention to address the target language being taught. Literary texts are rich in meaning, and they have suggestive power. Taking to mind this, different genres of literary texts were incorporated in preparatory students' text book. Here stated below shows that the statistical response of the students' on the texts relation with the unit topic.

\begin{tabular}{|c|c|c|c|c|c|c|c|c|c|c|c|}
\hline \multirow[t]{2}{*}{ No } & \multirow[t]{2}{*}{ Literary texts } & \multicolumn{2}{|c|}{ Strongly Agree } & \multicolumn{2}{|l|}{ Agree } & \multicolumn{2}{|l|}{ Neutral } & \multicolumn{2}{|l|}{ Disagree } & \multicolumn{2}{|c|}{ Strongly Disagree } \\
\hline & & Frequency & Percent & Frequency & Percent & Frequency & percent & frequency & percent & Frequency & percent \\
\hline 1 & The au anthem & 93 & 27.9 & 105 & 31.5 & 36 & 10.6 & 20 & 6 & 47 & 14.1 \\
\hline 2 & $\begin{array}{l}\text { Oweka learns a } \\
\text { lesson }\end{array}$ & 26 & 7.8 & 61 & 18.3 & 63 & 18.9 & 76 & 22.8 & 75 & 22.5 \\
\hline 3 & $\begin{array}{l}\text { Night of a } \\
\text { scorpion }\end{array}$ & 31 & 9.3 & 58 & 17.4 & 76 & 22.8 & 77 & 23.1 & 59 & 17.7 \\
\hline 4 & Operation rhino & 25 & 7.5 & 78 & 23.4 & 82 & 24.6 & 67 & 20.1 & 49 & 14.7 \\
\hline 5 & -mingual street & 20 & 6 & 36 & 10.8 & 105 & 31.5 & 93 & 27.9 & 47 & 14.1 \\
\hline 6 & -Tale of a tap & 23 & 6.9 & 69 & 20.7 & 49 & 14.7 & 124 & 37.2 & 36 & 10.8 \\
\hline 7 & -the African child & 15 & 4.5 & 96 & 28.8 & 51 & 15.3 & 65 & 19.5 & 74 & 22.2 \\
\hline 8 & $\begin{array}{l}\text { Why old woman } \\
\text { limps }\end{array}$ & 12 & 3.6 & 64 & 19.2 & 15 & 4.5 & 81 & 24.3 & 38 & 11.4 \\
\hline 9 & The narrow path & 23 & 6.9 & 43 & 12.9 & 29 & 8.4 & 59 & 17.7 & 51 & 15.3 \\
\hline 10 & $\begin{array}{l}\text { building the } \\
\text { nation }\end{array}$ & 12 & 3.6 & 31 & 9.3 & 62 & 18.6 & 79 & 23.7 & 26 & 7.8 \\
\hline 11 & Vultures & 18 & 5.4 & 38 & 11.4 & 35 & 10.5 & 84 & 25.2 & 35 & 10.5 \\
\hline 12 & The money order & 4 & 1.2 & 57 & 17.1 & 39 & 11.7 & 82 & 24.6 & 28 & 8.4 \\
\hline 13 & Total & 277 & 7.55 & 739 & 18.4 & 642 & 16 & 907 & 22.65 & 565 & 14.13 \\
\hline
\end{tabular}

The purpose of the literary texts in students' text book is supporting the unit since they are contributing a lot for the students' language competence as well as the developing their thinking ability. In this context, the literary texts should be related with the unit topic which they supply additional lesson. The respondents $105(31.5 \%)$ stated that they agree on the relationship between the text 'The Au Anthem' and the unit of the topic, 'The AU'. In addition,93(27.9\%) of the respondents strongly agree that the unit topic and the literary text,. Thus, the majority of the respondents argued that the literary text, 'The Au Anthem' is the extension of the unit topic. This text strengthening the unit topic since the main issues of it directly deals with the unit topic and gives lesson to the learner about the 'AU'. One of the targets of literary text in language teaching is increasing the involvement of the learners with exposure to the real environment. Another text 'Oweka learns a lesson', the respondents76 (22.8\%)and 75(22.5\%) of the respondents disagree and strongly disagree on the text's relation to the unit topic, Education respectively. Here. Most respondents believed that the literary text is not related to the unity of the text book. On the other hand, 61(18.3\%) of the respondents said that the text is related to the unit topic, and 63(18.9\%) of the respondents have neutral position on the relationship between the literary text and the unit topic. On the text Night of a scorpion, 77(23.1) and 59(17.7\%) of the respondents disagree and strongly disagree on the texts relation to the unit topic respectively. Unlike to this, $76(22.8 \%)$ of the respondents have neutral position to the relation between the text and the unit topic. Thus, the most of the respondents confirmed that the text and the unit topic, traditional and modern medicine are not related. Under the unit tourism, the literary text is 'Operation rhino'. For this text, 78 (23.4\% of the respondents agree that it has relationship with unit topic; whereas, $82(24.6 \%)$ of them have neutral position in this regard. On the other hand, $67(20.1 \%)$ of the respondents disagreed on the relationship between the text and the unit topic.

Under the unit topic fiction, the literary text is the 'Mingual Street' the respondents $105(31.5 \%)$ said that they have neutral position with regard to the relationship between the text and the unit topic. Thus, most of the respondents could not decide whether the text is related the unit or not. But 93(27.9\%) of the respondent confirmed that they disagree on the text's relation to unit topic. As stated in the above table no.5, majority of respondents believed that the 'Mingual Street' is not related with the unit topic fiction. Similarly, 124(37.2\%) of the respondents disagreed on the text, Tale of a tap relation to unit topic water. These respondents found the text unrelated with the unit topic. This means that the issue of the text is different from the objective of the unit topic even if the sub topics of the unit should support the main topic of the unit and should give detail information to the learners. Most respondents, therefore, stated that the lesson of the literary text is related with the unit topic, water. On another text (the African child) 65(19.5\%) and 74(22.2\%) of the respondents disagree and strongly disagree on relation to the unit topic. Similar to Tale of a tap, the African child is found under the unit of water andmore than half of the respondents confirmed that this text is not related the unit. Moreover, $81(24.3 \%)$ of the respondents sated that they disagree on the text Why old woman limpswith the unit topic poverty and development. Unlike to this, 64(19.2\%)of the respondents indicated that the text is related with the unit topic.

Respondents stated the literary texts are not related with the unit topic in which they found in preparatory English for Ethiopian students' text books. In line with this, $17.7 \%, 23.7 \%, 25.2 \%$, and $24.6 \%$ of the respondents disagree on the texts, The narrow path, building the nation, Vultures and The money order with the respective of each unit topic respectively. 
Including text in language class enables the learners to make the target language practical. The content of the selected text is expected to support the unit of the text book, but the study showed that most of the literary texts are unrelated with the unit topic. Among the respondents, 54.08\% of them agreed that the unit topic and the literary texts are thematically unrelated. The goal of inserting texts on the syllabus of language is to reinforce the theoretical and to make it practical.

Of the issue, the purposes of utilizing literary texts in language class is to apply the theoretical language concepts in the context of the lesson being learnt, but the above statistical data indicates that reverse of this because only $25.59 \%$ of the respondents agreed on the relationship between the unit topic and the subject matter of the text. Since most of respondents did not agree on relationship between the literary text and unit topic of the text books. In such way, the inclination of the literary texts becomes ambiguous to the learners. The students may not realize the target language effectively as they expected on the stated objective of the unit.

From the total respondents of each literary text, the average $22.65 \%$ of the respondents disagreed on each literary texts relation to the unit topic. This number demonstrates the average percentage of the respondents for 12 literary texts in both grade $11^{\text {th }}$ and $12^{\text {th }}$ students' text books. As mentioned in the above text, the highest percent of the respondents did not agree on the issue of literary text with each respective unit. On the other hand, $18.4 \%$ of the respondents agreed on the texts relation with the unit topic. However, some of the respondents believed that the literary texts are related with the unit topic, majority of them did not agree on this issue.

\section{FGD Analysis}

Teachers who have participated in the FGD have affirmed that they somehow recognize the merit of using literary materials in language teaching classes. They appear to know that literary materials are not only authentic but also attractive. Yet, they admitted that the materials are tough for both the teachers and the students. The problem emanates from poor material design and from the fact that the teachers do not have a dependable training on how to make the most out of literary recourses. This makes the materials more of a frustrating to both the teacher and the learner against the belief that the resources will be charming.

Teachers who taught English subject in grade $11^{\text {th }}$ and $12^{\text {th }}$ were participated in focus group discussion in regard to literary texts in the preparatory students English text books. The first discussion question was do you believe it is good to include literary resources in language texts? For this question all of the respondents had similar response. They said including literary texts in the language class develops the learners' language competence in different aspects. Since the literary texts are rich in language, they help to the learner to develop basic and micro skills of English language. In addition to the language aspect, the texts provide the learner personal experience. For one thing, the texts depict the psychological and ideological development and the motive of the employed character. From this, the learners share experience and widen their view of horizon beyond the aspiration of the character. Another point that consuming literary text, helps the learner to reinforce humanity and to be communicative and logical in their life career.

\section{CONCLUSIONS AND RECOMMENDATIONS}

\section{A. Conclusions}

It is widely recognized that using literary resources in language teaching classes is meritorious for its authenticity and charming nature naturally embedded in such materials. In view of this, English for Ethiopia, student text Books for grades 11 and 12 have duly included literary materials of different genres to be exploited for teaching the different macro and micro skills of language. As this study has shown, the language teachers who participated in the study recognize that literary materials have been included sufficiently. Unfortunately, the materials are cursed to be overlooked because the teachers find them frustrating as they have no dependable capacity to design tasks and exploit the literary resources. In addition, most of the texts are difficult to understand. As the students reported, most of the literary texts are unrelated with the unit topic. Along this, the texts are culturally distant from the learners' culture.

\section{B. Recommendations}

Based on the findings, the literary texts should be manageable interims of language difficulty. The type of the texts must be related with the unit topic. The literary texts should be culturally familiar to both the students and the teachers. In general, curriculum designers should take into account needs, motivation, interests, cultural background and language level of the students. It is recommended that trainings shall be given to the teachers on how to handle such recourses. It is also advisable if similar studies are made more rigorously including better samples and applying other relevant methodologies.

\section{REFERENCES}

[1] Abiy Y. (2013). High School Students' Writing Skills and their English Language Proficiency as Predictors of their English Language Writing Performance Ethiop. J. Educ. \& Sc. Vol. 9, 1.51-60

[2] Afolayan, A. (1972). The relevance of language study for the teaching and learning of English Literature in Nigeria. JNESA, Vol. 5, Nos. 1 \& 2 . 
[3] Aly A. (2012). Using Literature in Reading English as Second/Foreign Language Tanta University, Egypt. Retrieve https://www.google.com/search?source= hp\&ei=cvLeWrelOoXvUoP3nPgH\&q (accessed 18/04/2016).

[4] Babaee, R. \&Yahya, W. (2014). Significance of literature in foreign language teaching. International Education Studies, 7(4), $80-85$.

[5] Collie J. \$ Slater S. (1990). Literature in the Language Classroom. A Resource Book of Ideas and Activities, Cambridge Handbooks for Language Teachers.

[6] Kohzadi, H., Azizmohammadi, F. \&Sanadi, F. (2014). Is there a relationship between critical thinking and critical reading of literary texts: A case study at Arak Unversity (Iran). International Letters of Social and Humanities Sciences, 33, 63-76.

[7] Kramsch C. (1993). Context and Culture in Language Teaching. Oxford: Oxford University Press. 235-251

[8] McKay. S. (1982). Literature in the ESL Classroom. TESOL Quarterly, 16, 4, 529-536.

[9] Mebratu M. (2015). The status, roles and challenges of teaching English language in Ethiopia context: the case of selected primary and secondary schools in Hawassa University technology village area. International Journal of Home Science 2015; $1(2), 07-11$.

[10] Miller, S. M. (2003). How literature discussion shapes thinking: ZPDs for teaching/learning habits of the heart and mind. In Kozulin, A. (Ed.), Vygotsky.s educational theory in context: Learning in doing (pp. 289-316). U.K., New York: Cambridge University Press.

[11] Mohammad. K, Amir H. Rahimi. (2012). Literature and Language Teaching. Journal of Academic and Applied Studies :Vol. 2.6, 213-218

[12] Mokhtari, R. (2014). The comparative study of literary vs. non-literary text and Iranian EFL learners' performance on cloze tests of inference. Journal of Language Teaching and Research, 5(1), 215-220.

[13] Obediat, M. (1997). "Language vs. Literature in English Departments in the Arab World" in English Teaching Forum 35, no. 1, USA, 30-37.

[14] Paffard, M. (1978). Thinking about English. England: A Member of the Pentos Group.

[15] Roe, B. D. \& E. P. Ross. (2010). Benefits of literature. Retrieved from http://www.education.com/reference/article/benefitsliterature(accessed 16/4/2016).

[16] Sage, H. (1987). Incorporating Literature in ESL Instruction. New Jersey: Prentice-Hall, Inc.

[17] Sii L. Mee L., Chen Siew E.(2016).Types of English Literature Teaching Approaches Preferred by Teachers in Secondary Schools in Miri, Sarawak. International Journal of Language Education and Applied Linguistics (IJLEAL).2016.4, 1-14.

[18] Teshome, D. (2001). Assessment of Pupils Achievements in the Teaching of English Training and Practice in focus. The Ethiopian Journal of Education. , Vol.21 No 1, 25-47.

[19] Webb \$ Barbara. (2003). English for Ethiopia, student text book, grades11and 12. Ministry of Education. Pearson Education Limited. England.

Gedefaw Abie Kebede was born on July 1987 in Amhara Regional state, Ethiopia. He has gotten his BA degree in English Language Literature from Arba Minch University, Ethiopia since 2010. Then, he studied English Literature in Mekelle University, Ethiopia and graduated with MA degree in 2012.

He has been teaching different literature courses since 2012 at Debre Markos University, Ethiopia. His major field is narratology, and he published an article on the title Narrative Time in the Beautiful Things that Heaven Bears in 2014. Currently, he teaches English literature at Debre Markos University, Ethiopia, and he conducts research in the field of narratolagy and folklore.

Yihenew Melesse Milkitie was born in Amhara Regional state, Ethiopia. He has gotten his BA degree in English Education from Bahir Dar University, Ethiopia. Then, he studied English Literature in Addis Ababa University, Ethiopia. He taught English in Debre Markos Teachers College, and now he is a lecturer at Debre Markos University. 